\title{
AUTONOMIA/MUTUALIDADE NA ASSISTÊNCIA DE ENFERMAGEM
}

Maria Lúcia Araújo Sadala*

SADALA, M. L. A. Autonomia/mutualidade na assistência de enfermagem. Rev.Latino-am.enfermagem, Ribeirão Preto, v. 4, n. 1, p. 111-17, janeiro de 1996.

Utilizando um estudo de caso como ilustração, a autora discute as possibilidades da participação ativa dos pacientes na assistência à saúde, visando estimulá-los ao autocuidado. A partir de considerações sobre as formas tradicionais e autoritárias da assistência à saúde nos quais os profissionais determinam os procedimentos e os pacientes aceitam passivamente o que Ihes é determinado, $o$ estudo discute as questões da dependência e independência da enfermeira e do cliente no processo saúde-doença, propondo uma inter-relação que mantenha a autonomia de um e de outro. No sentido de que ambos participem ativamente do processo de enfermagem. Tal postura entre a autonomia e a mutualidade é descrita como uma relação dialética entre duas pessoas que se percebem nas suas especificidades e potencialidades, tendo como objetivo comum desenvolver uma assistência de enfermagem que contempla os valores éticos e humanísticos.

UNITERMOS: cuidados de enfermagem, relacionamento enfermeira-paciente, autocuidado

Existe pelo menos um aspecto universal e democrático no nosso sistema de saúde. Todos os nossos dentes são chamados pelo nome de paciente. Qualquer que seja a sua patologia, ou mesmo que não apresente patologia. Qualquer que seja a sua condição sócio-econômica, cultural, idade, nível de consciência. Hospitalizado ou ambulatorial. Basta que dê entrada numa instituição de saúde. O que é ser paciente?

*Professora Responsável pela Disciplina Relacionamento Enfermeira-Paciente do Curso de Enfermagem F. M. Botucatu, UNESP 
Para FERREIRA (1973), paciente significa resignado, sofredor, manso; pessoa que padece ou vai padecer; doente, aquele que recebe a ação praticada por um agente.

Entre nós, na apenas se nomeia o doente de paciente. Ele é tratado como tal, aquele que recebe o cuidado. É o objeto das ações. Faz parte de uma relação desigual, na qual os profissionais determinam a direção. Um exemplo explícito desse procedimento refere-se ao prontuário do doente: em qualquer instituição de saúde, é definitivamente proibido ao paciente ter acesso ao que nós profissionais de saúde escrevemos sobre ele.

Essa prática, tão freqüente em nossa cultura, leva o cliente a assumir a posição que se espera dele: o paciente, o ser passivo e dependente que se submeterá aos tratamentos que Ihe serão determinados. Por outro lado, esse ser passivo e dependente espera que o profissional resolva todos os seus problemas de saúde o mais rapidamente possível, com o menor custo e desconforto. Ambas as expectativas, a do profissional e do cliente, assim descritas, inclui um componente mágico: se tivermos, de um lado, um paciente suficientemente cooperativo e, do outro lado, um profissional competente, disso resultará a recuperação da saúde de forma imediata (SUNDEEN, 1994).

Mesmo sabendo, pela formação e pela prática, que as coisas não se passam assim, que os resultados depende de uma rede intrincada de elementos que condicionam o sistema de saúde, dentro da complexidade do sistema sociocultural, tudo indica, da forma em que se processam os atendimentos na área de saúde, que o autoritarismo e o paternalismo determinam, os nossos procedimentos. Como se toda uma estrutura antiga e persistente, toda uma história secular de dominação socioeconômica e cultural reproduzisse, até os dias de hoje, a hegemonia de alguns indivíduos sobre os outros. $\mathrm{Na}$ área da saúde, isso se justificaria em nome de um conhecimento científico que o profissional de formação universitária detém e que os seus assistidos não detém, portanto, aquele sabe o que é bom para estes. SADALA (1992) ilustra nosso parecer com o seguinte caso:

Uma jovem puérpera registrou uma criança de uma semana num posto de saúde, a fim de acompanhar as atividades propostas pelo Programa de Saúde da Criança, ou seja, vacinações, acompanhamento de seu crescimento e desenvolvimento e orientações sobre os cuidados com a criança. Mãe e criança deveriam freqüentar consulta médica e atendimento de enfermagem programadas mensalmente, ou quando se fizesse necessário. As orientações à mãe consistiam principalmente em incentivar o aleitamento materno exclusivo até os seis meses de idade. No primeiro mês de acompanhamento, a mãe procurou pela enfermeira do serviço a cada três dias. Motivo: supunha que seu leite fosse insuficiente para a criança, uma vez que ela chorava muito, mesmo após as mamadas, e parecia não ganhar peso. A enfermeira insistiu na importância do leite materno e propôs-se a acompanhar a evolução da criança a cada dois dias. Seu objetivo era demonstrar à mãe o ganho de peso da criança. Isso foi feito, e provou-se que o RN apresentava 
uma curva de peso dentro do esperado. "Portanto", disse a enfermeira à mãe, "está evidente que o seu leite está sendo suficiente para a sua criança. Aliás, é o que de melhor você pode oferecer a ele, o seu leite para o seu bebê". A mãe continuou a freqüentar o posto de saúde a cada dois, três dias, queixando-se do choro da criança, das brigas com os pais, com os quais morava, por causa do choro, e insistindo em que seu leite não era bom. Entre os profissionais do serviço - enfermeira, médico, auxiliares - a jovem mãe já fora rotulada de "difícil" e era olhada desta forma.

A enfermeira, pacientemente, repetia-lhe as orientações sobre a importância do aleitamento materno. Este era o ponto principal do Programa de Saúde da Criança.

Nesse serviço, havia uma estatística promissora de como estava crescendo o número de mães que conseguiam amamentar seus bebês exclusivamente ao peito até os seis meses de idade. Porém, a jovem mãe continuava manifestando um comportamento de ansiedade e pedindo que se complementasse a alimentação do seu filho com mamadeira. Até o momento em que disse à enfermeira com uma expressão muito ansiosa "A senhora permite que eu dê mamadeira ao meu filho?".

Quando a questão ficou explícita para a enfermeira, quando o papel que ela estava desempenhando neste processo lhe foi mostrado - um papel de juiz - ela começou a refletir sobre a relação de autoritarismo que estava desenvolvendo com a cliente. E não apenas com esta cliente, mas com todas as demais do Programa de Saúde da Criança, com as mulheres do Programa de Saúde da Mulher, e do Adulto, e assim por diante. Em nome de programas para a promoção da saúde, que são realmente importantes para a comunidade, o que se tem feito de forma autoritária, negando às pessoas o seu direito de falar e decidir sobre o seu corpo?

Encontramos em HEIDEGGER (1981) a descrição das várias formas de "cuidar" do outro. Dentre elas, destacamos duas por serem relevantes para o presente estudo: uma seria o tomar conta do outro, "saltar sobre o outro", tornando-o dependente e dominado, na verdade, fazendo pelo outro o que este deveria fazer. É como vemos a atenção da enfermeira junto à jovem puérpera, assim como a dos demais profissionais. Há um projeto a ser desenvolvido - a estimulação ao aleitamento materno - e este programa será promovido indistintamente a todas as mães que recorrem ao serviço. É importante que ela amamente o seu filho, e tudo será feito nesse sentido. É o melhor para ela e para a criança. A outra forma, descrita por HEIDEGGER (1981), refere-se a um cuidar que faz com que o outro se volte para si mesmo, perceba-se a si próprio em sua possibilidade-para-ser. Na história da jovem puérpera, esse cuidar envolveria estimular a expressão das necessidades da mulher, as suas dificuldades em se ver como a mãe-que-amamenta, oferecer-Ihe as orientações para que, dentro de suas possibilidades e limitações, ela se encontrasse. E encontrasse a sua possibilidade de amamentar. Ou não. Parece-nos que esta é a forma de cuidar que educa, no sentido de levar a pessoa a assumir-se como responsável por si mesma. Falamos, neste caso, da autonomia da pessoa no seu próprio cuidado, no cuidado da sua saúde. É o direito e o dever do cidadão para com o seu próprio corpo. 
Há dez anos, não seria possível falar sobre a autonomia do cliente, na assistência à saúde. Atualmente, os cidadãos adquiriram um "status" de "mais cidadãos". O cliente, como consumidor, tem se tomado mais crítico a respeito dos cuidados que lhe são providenciados. SUNDEEN (1984) descreve este fato nos EUA e, no Brasil, ainda que aos poucos, num processo lento, mais evidente nas camadas média e alta, observa-se um acordar para a percepção dos direitos como pessoa. Tomam-se mais freqüentes e conhecidos os processos judiciários envolvendo situações de assistência à saúde. Para acompanhar tais mudanças da sociedade, há que mudar o sistema de saúde, assim como a formação dos profissionais que atuam na área. Alterações recentes no Código de Ética de Enfermagem (art. 26, 27 e 28) refletem, claramente, a conquista dos direitos do cidadão brasileiro como consumidor na situação de usuário desse sistema.

Na enfermagem, observamos, predominantemente nos meios acadêmicos, a preocupação, cada vez maior, em estimular uma relação profissional que contemple o par enfermeira-paciente, no qual os dois participantes contribuem igualmente para o processo de cuidado à saúde (PATTERSON \& ZDERAD, 1976; HORTA, 1979; SUNDEEN, 1984). Muito embora restrita aos cursos de graduação e mostrando-se, freqüentemente, como um reflexo da influência da enfermagem dos países de primeiro mundo, a preocupação crescente com o papel do paciente no processo de enfermagem evidencia a emergência de um movimento em resposta à aquisição, pelos brasileiros, dos seus direitos como cidadãos.

A compreensão dos sentimentos de dependência, independência e interdependência, descritos por SUNDEEN (1984), na relação que se estabelece entre a enfermeira e o cliente, leva aos conceitos de autonomia e mutualidade entre ambos. A autonomia refere-se à habilidade da autodeterminação, de ser independente. A mutualidade envolve um processo de compartilhar com outra pessoa. Superficialmente, podem parecer exclusivos. Porém, numa visão dialética, podemos percebê-los como elementos de um processo, partes que interagem num "continuum". É importante terem mente que os indivíduos, ao se relacionarem com os demais e com o ambiente, mudam o seu grau de abertura para a autonomia e para o comportamento de reciprocidade, de acordo com as circunstâncias que vivenciam. Na área da saúde, tais variações ocorrem de indivíduo para indivíduo, de situação para situação. Um cliente hipertenso, adulto, ativo, por exemplo, apresentará um alto nível de autonomia e um menor de mutualidade. Por outro lado, um cliente acamado, num leito hospitalar, dependendo da enfermeira para várias atividades, apresentará um nível menor de autonomia e um maior de mutualidade. Mesmo em situação de grande dependência, como de um recémnascido, por exemplo, haverá níveis de autonomia: há que se observar, atentamente, as reações da criança, os seus sinais e sintomas, e perceber o que eles comunicam da criança: fome, frio, dor, para que a sua autonomia -a sua individualidade -seja respeitada no mais alto grau.

Vale que se pondere como, nessa condição, se manifesta a autonomia do profissional frente ao cliente que decide, por si, o que é bom para ele. Vemos as duas 
autonomias, a do profissional e a do cliente, numa interação dinâmica, uma se sobrepondo à outra, sob determinadas circunstâncias e momentos. Em alguns, o foco incidirá sobre o profissional, quando a situação exigir dele procedimentos técnico-científicos específicos da sua competência. Em outros, o foco recairá sobre o cliente, que se expressará sobre as suas peculiaridades, sobre as suas necessidades, sobre o seu querer. Da interação das duas autonomias resultará a mutualidade no cuidado. É a percepção, pelo profissional, de quanto é dependente do paciente. $E$ independente, no que se refere à sua área específica. Trata-se da compreensão do significado da interdependência entre o profissional e o cliente.

Pode-se afirmar, seguramente, que, em todas as interações de enfermagem, nos deparamos com a interdependência profissional-cliente. A mutualidade acontece, na medida em que olhamos para o cliente como uma pessoa, dona do seu próprio corpo e responsável pelo seu autocuidado. Quando orientamos a mãe de uma criança proveniente da zona rural, fazendo uma exposição impecável sobre a necessidade dos alimentos nutritivos essenciais ao crescimento e ao desenvolvimento da sua criança, estaremos exercendo plenamente nossas funções técnicas. Porém, se não procuramos, antes, conhecer o que ela pensa sobre isso, como ela faz isso e como ela pode fazer isso, e, principalmente, se ela sente que isso é um problema importante para a criança, estaremos apenas impondo-lhe a nossa forma de lidar com esses conceitos, mesmo que representem uma verdade cientificamente comprovada. WILLIAMSON (1981) fundamenta a participação do cliente no autocuidado, através de alguns pressupostos:

- O indivíduo tem direito à autodeterminação em relação a participar ou não do tratamento que lhe é proposto pelos profissionais de saúde. Inicialmente, portanto, é necessário indagar daquela mãe de zona rural sobre o seu interesse em participar de atividades de orientação sobre a nutrição do seu filho.

- O cliente e o profissional interagem dinamicamente no sistema de saúde, deforma recíproca, um influindo sobre o outro. A abordagem compreensiva do cliente, como ser humano dotado de um conhecimento próprio, resultante da sua experiência de vida, permite que o profissional aprenda com ele, saindo da posição de detentor de um conhecimento técnico indiscutível. Podemos aprender com essa mãe de zona rural formas interessantes de atender às necessidades protéicas e calóricas da criança, um modo que ela descobriu como possível e eficiente no seu contexto. Por outro lado, podemos fornecer-Ihe orientações técnicas que a ajudarão a aprimorar a sua prática.

- A pessoa, não o profissional, é responsável por sua própria saúde. Na medida em que estimulamos a participação do cliente no seu tratamento e na conservação de sua saúde, fica explicitado para ele que lhe cabe essa responsabilidade. Nesta situação, ao profissional cabe orientar o cliente sobre os conhecimentos técnicos, para que o mesmo reconheça suas possibilidades e assuma a opção que melhor atenda às suas necessidades.

- O conceito de saúde do indivíduo é legítimo e como tal deve ser respeitado. Este 
conceito está relacionado às condições socioculturais das pessoas e à sua experiência de vida. Sabe-se que esses são elementos que não se conseguem alterar artificialmente. Podemos não concordar com tais conceitos e fundamentar os nossos, mas a compreensão do significado das experiências pessoais do outro se impõe numa relação de reciprocidade. As trocas entre o cliente e o profissional afetarão a ambos, haverá mudanças de posição dos dois lados, mas para que a comunicação se efetive é necessário cada um respeitar a posição do outro.

A aceitação de tais pressupostos pelo profissional de saúde depende, diretamente, dos objetivos que ele estabelece na sua relação com o cliente, e do seu conceito de cuidado de enfermagem.

A enfermagem, descrita por PEPLAU (1968) como um relacionamento entre o profissional preparado formalmente para prestar cuidados específicos e uma pessoa que precisa de ajuda, certamente será mais bem sucedida quando paciente e profissional participarem ativamente do processo de assistência. $O$ cliente tem 0 conhecimento de si mesmo e de suas necessidades. O profissional domina os conhecimentos técnico-científicos que Ihe possibilitam identificar os problemas do cliente e implementar os procedimentos para resolvê-los. Podemos atingir um nível terapêutico de autonomia quando a autonomia do doente não bloqueia a ação do profissional e quando a autonomia do profissional não bloqueia a autodeterminação do cliente (SUNDEEN, 1984).

$\mathrm{Na}$ autonomia/mutualidade da assistência de enfermagem a ênfase está no pressuposto de que o cliente é um ser humano único, com as suas peculiaridades e potencialidades de crescimento através de um relacionamento de ajuda. Neste sentido, a relação de interdependência se propõe para todo e qualquer cliente, qualquer que seja a sua patologia, condição sociocultural, condição física, idade, considerando-se sempre o nível de consciência e capacidade de cada um, na situação particular vivenciada no momento.

\section{AUTONOMY/MUTUALITY IN NURSING CARE}

Taking into consideration the traditional official health assistance forms, the present paper discusses questions related to dependence and independence of nurse and patient in the health/illness process. Under that perspective it proposes a relationship that preserves the autonomy of one and the other, so that both can participate in the process of nursing and self-care.

UNITERMS: nursing autonomy and mutuality, patient-nurse relationship, self-care 


\section{AUTONOMÍA/PARTICIPACIÓN MUTUA EN LA ASISTENCIA DE ENFERMERÍA}

Teniendo como referenciales principales las consideraciones sobre las formas tradicionales y autoritarias en la asistencia a la salud, la autora discute las cuestiones de la dependencia e independencia de la enfermera y del enfermo en el proceso salud-enfermedad. Dentro de esto concepto se propone una relación de interdependencia en la cual se mantengan la autonomía de uno y de otro de forma que los dos tengan participación activa en el proceso de enfermería.

UNITERMOS: relaciones enfermera-paciente. cuidado de enfermería, interdependencia entre enfermera y paciente

\section{REFERÊNCIAS BIBLIOGRÁFICAS}

01. CÓDIGO DE ÉTICA DOS PROFISSIONAIS DE ENFERMAGEM. São Paulo: Coren SP., 1993, p. 11.

02. FERREIRA, A. B. H. Pequeno dicionário brasileiro de língua portuguesa. São Paulo: Companhia Editora Nacional, 1973.

03. HEIDEGGER, M. Todos nós...ninguém: um enfoque fenomenológico do social/Martin Heidegger: apresentação e introdução, Solon Spanoudis. Tradução e comentários Dulce Mara Critelli. São Paulo: Moraes, 1981.

04. HORTA, W. A. Processo de enfermagem. São Paulo: EPU, 1979.

05. PATTERSON, O.; ZDERAD, L.T. Humanistic nursing. New York, John Wyley \& Sons, 1976.

06. PEPLAU, H. E. Principios básicos para la orientación del paciente. Washington: OPAS/OMS, 1968.

07. SADALA, M. L. A. Comunicação com a mãe que amamenta: um estudo de caso. In: SIMPÓSIO BRASILEIRO DE COMUNICAÇÃO EM ENFERMAGEM. Anais. Ribeirão Preto, 1992.

08. SUNDEEN, S.J. et al. Nurse client interaction: implementing the nurse process. Saint Louis: Mosby, 1984.

09. WILLIAMSON, J. A. Mutual interaction: a model of nursing practice. Nurs.Outlook, v. 29, n. 3, p. 104, 1981. 